\title{
Dendritic Cells From the Cervical Mucosa Capture and Transfer HIV-1 via Siglec-1
}

\author{
Daniel Perez-Zsolt ${ }^{1,2+}$, Jon Cantero-Pérez ${ }^{3,4+}$, Itziar Erkizia ${ }^{1}$, Susana Benet ${ }^{1,2}{ }^{2}$, Maria Pino ${ }^{1}$, \\ Carla Serra-Peinado ${ }^{3}$, Alba Hernández-Gallego ${ }^{4,5}$, Josep Castellvi ${ }^{6,7}$, Gustavo Tapia ${ }^{4,5,7}$, \\ Vicent Arnau-Saz ${ }^{2,3}$, Julio Garrido ${ }^{8}$, Antoni Tarrats ${ }^{9}$, Maria J. Buzón ${ }^{3}$, \\ Javier Martinez-Picado ${ }^{1,10,11}$, Nuria Izquierdo-Useros ${ }^{1,4 *}$ and Meritxell Genescà ${ }^{3,4 * \neq}$ \\ ${ }^{1}$ IrsiCaixa AIDS Research Institute, Badalona, Spain, ${ }^{2}$ Department of Biochemistry and Molecular Biology, \\ Universitat Autònoma de Barcelona, Barcelona, Spain, ${ }^{3}$ Department of Infectious Diseases, Vall d'Hebron Institut de \\ Recerca, Barcelona, Spain, ${ }^{4}$ Institut d'Investigació en Ciències de la Salut Germans Trias i Pujol, Badalona, Spain, \\ ${ }^{5}$ Pathology Department, Hospital Universitari Germans Trias i Pujol, Badalona, Spain, ${ }^{6}$ Pathology Department, Hospital \\ Universitari Vall d'Hebron, Barcelona, Spain, ' Department of Morphological Sciences, Universitat Autònoma de Barcelona, \\ Barcelona, Spain, ${ }^{8} \mathrm{Hospital}$ Municipal de Badalona, Badalona, Spain, ${ }^{9}$ Department of Obstetrics and Gynecology, Hospital \\ Universitari Germans Trias i Pujol, Badalona, Spain, ${ }^{10}$ University of Vic-Central University of Catalonia (UVic-UCC), Vic, Spain, \\ ${ }^{11}$ Institució Catalana de Recerca i Estudis Avançats, Barcelona, Spain
}

Antigen presenting cells from the cervical mucosa are thought to amplify incoming HIV-1 and spread infection systemically without being productively infected. Yet, the molecular mechanism at the cervical mucosa underlying this viral transmission pathway remains unknown. Here we identified a subset of HLA-DR ${ }^{+} \mathrm{CD} 14^{+} \mathrm{CD} 11 \mathrm{C}^{+}$cervical DCs at the lamina propria of the ectocervix and the endocervix that expressed the type-l interferon inducible lectin Siglec-1 (CD169), which promoted viral uptake. In the cervical biopsy of a viremic HIV-1+ patient, Siglec-1+ cells harbored HIV-1-containing compartments, demonstrating that in vivo, these cells trap viruses. Ex vivo, a type-I interferon antiviral environment enhanced viral capture and trans-infection via Siglec-1. Nonetheless, HIV-1 transfer via cervical DCs was effectively prevented with antibodies against Siglec-1. Our findings contribute to decipher how cervical DCs may boost HIV-1 replication and promote systemic viral spread from the cervical mucosa, and highlight the importance of including inhibitors against Siglec-1 in microbicidal strategies.

Keywords: cervix, Siglec-1, HIV-1, trans-infection, myeloid cells

\section{INTRODUCTION}

Women account for 51\% of people living with HIV worldwide, and in 2017 this represented 18.8 million of females (1). Since HIV-1 infection is mostly acquired by sexual transmission (2), understanding the female genital tract immunobiology is imperative not only to halt novel infections, but also to design strategies that will limit HIV-1 spread within the mucosa and contain the virus during the early stages of infection. HIV-1 acquisition requires a series of orchestrated events that lead to systemic infection, beginning with viral entry through the genital epithelium and followed by the productive infection of distinct $\mathrm{CD}^{+}$target cells that reside within the mucosa. Local infection is early disseminated to draining lymph nodes, aiding to spread HIV-1 systemically and boost viral replication (3). While current antiviral agents are potent inhibitors of viral infection in the mucosa, efficacy of preventive methods is also critically dependent on effective blockade of all potential receptors involved in HIV-1 dissemination from the genital mucosa to the lymphoid tissues (4-6). Yet, the precise molecular mechanisms underlying viral dissemination routes from the genital mucosa that boost systemic HIV-1 infection remain unknown. 
Although productive infection during the first days after vaginal SIV exposure is low and mainly restricted to the cervicovaginal tissues (3), evidence for rapid dissemination to the draining lymph nodes has been demonstrated as soon as $24 \mathrm{~h}$ post-infection (7-9). These studies suggest a critical role for cervical myeloid cells and, particularly, dendritic cells (DCs) in the early dissemination of mucosal viruses to lymphoid tissues. Importantly, viral spread does not only rely on de novo productive infection of myeloid cells (10-12), but can be triggered upon activation of mucosal myeloid cells via the capture and storage of large amounts of HIV-1 particles that are later transferred to target cells, as previously reported for monocytederived DCs (13-15). Once mucosal myeloid cells migrate to secondary lymphoid tissues for induction of antiviral immune responses, trapped viruses can be efficiently transferred to $\mathrm{CD} 4^{+}$ $\mathrm{T}$ cells $(10,11)$, which become productively infected and fuel systemic viral dispersion. This highly infectious process is known as trans-infection, and pioneering work already identified that migratory HLA-DR ${ }^{+} \mathrm{CD}^{-}$cervical cells efficiently captured and transmitted HIV-1 in trans (5). Recent data also demonstrated that among all myeloid cell subsets, vaginal and cervical DCs capture and transport transmitted/founder viruses through the cervicovaginal mucosa and facilitate infection of target cells $(16,17)$.

Although trans-infection was initially attributed to the capacity of C-type lectin receptors such as DC-SIGN to specifically bind to the viral envelope glycoprotein of HIV-1 (11), viral capture in the female genital mucosa is independent of this particular receptor, as the majority of cervical DCs capturing HIV-1 do not express DC-SIGN (18) and neutralizing antibodies against DC-SIGN cannot block viral transmission (5). In addition to C-type lectin receptors, HIV-1 capture by myeloid cells is mediated by the sialic acid binding immunoglobulin-like lectin1 (Siglec-1/CD169) (19-21). This receptor potently enhances HIV-1 capture and storage in virus containing-compartments (22), that are later released from DCs to infect target cells via virological synapse formation (23). Siglec-1 is present on the surface of myeloid cells and its expression is potently enhanced by type-I interferon signaling $(21,24)$, which is triggered by viral immune sensing or bacterial lipopolysaccharide exposure, both factors associated to HIV-1 infection (25). However, it does not bind to the envelope glycoprotein of HIV-1 as C-type lectin receptors do (11), but recognizes sialylated gangliosides that are anchored on the viral membrane of enveloped retroviruses $(19,26)$. In vivo, Siglec-1 is required for robust infection and early dissemination of a retrovirus within the lymphoid tissue of a murine model (27), but its potential role during HIV-1 infection in the female genital tract remains unexplored.

Here we sought to clarify if trans-infection mediated by Siglec-1 could impact the early stages of HIV infection in women, and performed a comprehensive analysis of Siglec1 expression on human cervical anatomical compartments. In all samples studied, we identified mucosal DCs expressing this receptor, whose expression was boosted by interferon alfa (IFN $\alpha$ ) antiviral signaling. Moreover, we also found that cervical DCs enhanced viral capture and trans-infection, and that this mechanism was effectively prevented with antibodies against Siglec-1 receptor.

\section{RESULTS}

\section{Myeloid Cells From Human Cervical Submucosa Express Siglec-1}

We first analyzed Siglec-1 expression by flow cytometry on human cervical mononuclear cells obtained from tissues from benign hysterectomies processed immediately after prescribed surgery. Gating on hematopoietic $\mathrm{CD}_{4} 5^{+}$, single and viable cells allowed identifying myeloid $\mathrm{CD}^{-}{ }^{-} \mathrm{HLA}-\mathrm{DR}^{+}$cells (Figure 1A), which represented a mean of 6 and $7.5 \%$ of cells at the ectocervix and endocervix, respectively (red gate and bar graph, Figure 1B). Of note, HLA-DR ${ }^{-}$cells did not express Siglec1 (gray and brown gates, Figure 1C). However, among the myeloid HLA-DR ${ }^{+}$fraction, a mean of 24.5 and $11.5 \%$ of cells expressed Siglec-1 in the ectocervix and endocervix, respectively (blue gate and bar graph, Figure 1D). Moreover, these cells were predominantly CD11c $\mathrm{c}^{+} \mathrm{CD} 14^{+}$(pink gate and bar graph,

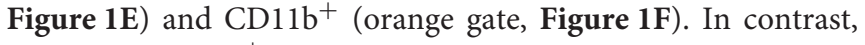
myeloid HLA-DR ${ }^{+}$cells lacking Siglec- 1 expression represented three distinct subsets: $\mathrm{CD} 11 \mathrm{c}^{-} \mathrm{CD} 14^{+}, \mathrm{CD} 11 \mathrm{c}^{+} \mathrm{CD} 14^{-}$and CD11c ${ }^{+} \mathrm{CD}_{14}{ }^{+}$cells (Figure 1G). Of note, Siglec- $1^{+}$cells displayed a higher activation status than Siglec- $1^{-}$cells as seen by HLA-DR expression levels (Supplemental Figure 1). These results identify Siglec- $1^{+}$myeloid cells at the ectocervix and endocervix as a subset that displays typical markers of interstitial cervical DCs, such as HLA-DR, CD11c, CD14, and CD11b (28).

\section{Siglec-1+ Cells Accumulate in the Submucosa of the Ectocervix and Endocervix}

To analyze the localization of Siglec- $1^{+}$cells within the cervix, we next performed immunofluorescence of mucosal tissues from women undergoing benign hysterectomies. Siglec- $1^{+}$cells predominantly located in the lamina propria or submucosa and, in agreement with flow cytometry data, were also positive for CD14 or CD11c (Figure 2A). In contrast, no Siglec- $1^{+}$ cells were found in the lower region of the epithelium, where CD207/langerin ${ }^{+}$Langerhans cells are commonly found (29). Immunohistochemistry staining of cervicovaginal tissues further identified Siglec- $1^{+}$cells displaying myeloid cell morphology mostly accumulated within the submucosa of the ectocervix, which is lined by a stratified squamous epithelium (Figure 2B, left). Siglec- $1^{+}$cells were also found in the endocervix, which is covered only by a single-layer columnar epithelium (Figure 2B, right), although the frequency was lower than at the ectocervix. However, in those endocervical tissues classified as highly inflamed based on histopathological detection of inflammatory infiltrates, we found a higher number of Siglec$1^{+}$cells (Figure 2C) that were comparable to those observed at the ectocervix (Figure 2B, left graph). Of note, the reasons for a higher inflammatory infiltrate could not be attributed to the HIV1 infection status, the level of viral load, age or any particular clinical indication for surgery (Table 1). These results identified the presence of myeloid cells expressing Siglec-1 in the steady state just beneath the mucosa of the ectocervix and endocervix, where cervical DCs usually accumulate (16). 


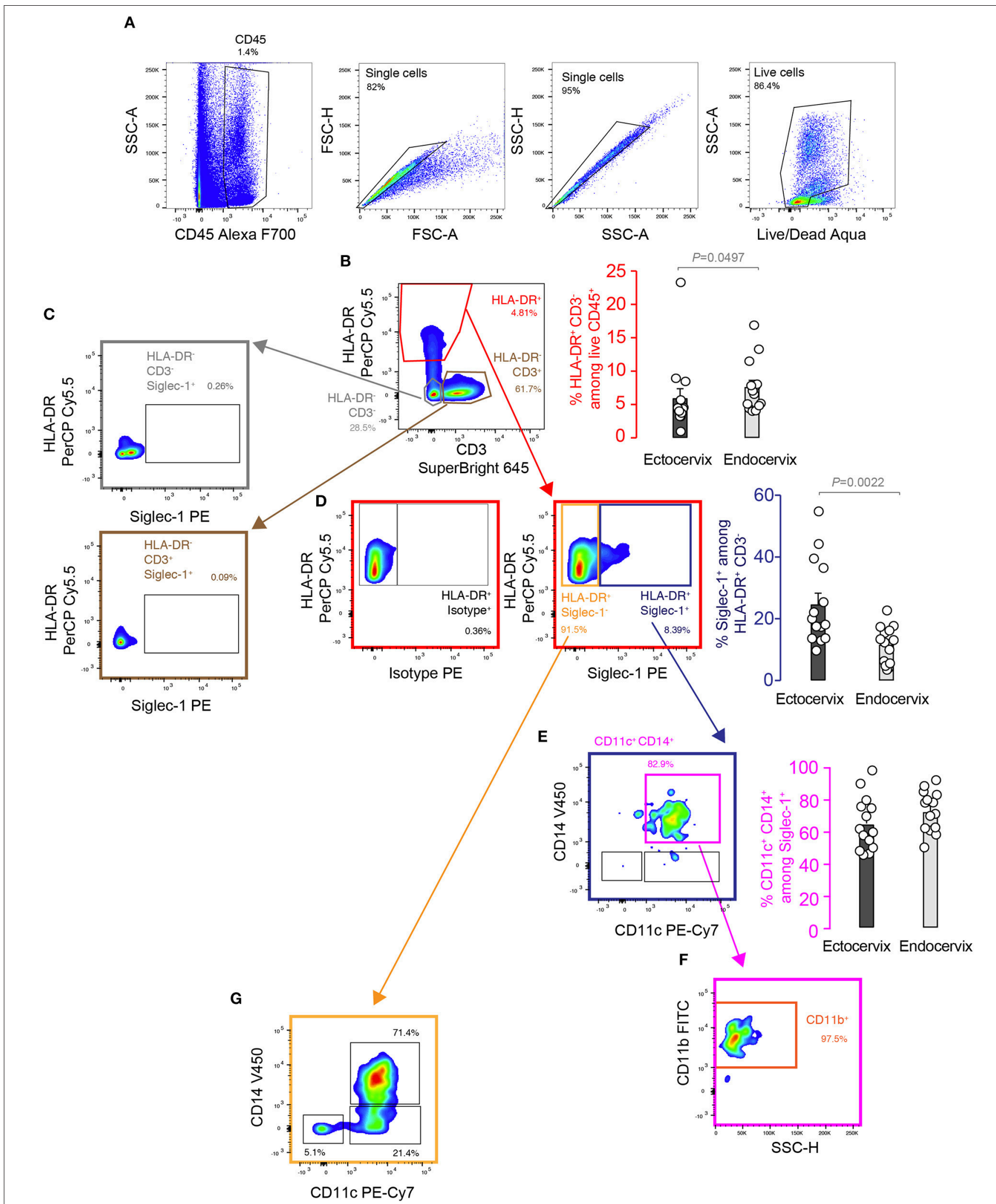

FIGURE 1 | Myeloid cells from human cervical mucosa express Siglec-1. FACS analysis and representative gating strategy of the cervicovaginal myeloid cell subsets. Colored gates and arrows indicate populations analyzed, and corresponding matching colors are used to identify bar graphs showing frequencies of those

(Continued) 
FIGURE 1 I populations. (A) Hematopoietic cells were identified by their CD45 expression, and single-live cells were selected by doublet discrimination and live/dead staining. (B) Representative dot plot and frequency of $\mathrm{HLA}_{-} \mathrm{DR}^{+}$and $\mathrm{CD}^{-}$on hematopoietic cells. (C) Representative dot plot showing that HLA-DR ${ }^{-}$cells do not express Siglec-1. (D) Representative dot plot and frequency of Siglec-1 expression analyzed in HLA-DR ${ }^{+}$myeloid cells compared to matched isotype control. (E) Representative dot plot and frequency of CD11 ${ }^{+}$CD14 $^{+}$cells among myeloid HLA-DR ${ }^{+}$cells expressing Siglec-1. (F) Representative dot plot of CD11b

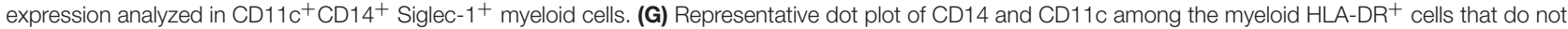
express Siglec-1. All bar graphs show mean values and SEM from 14 donors. Statistical differences were assessed with a Mann-Whitney test.
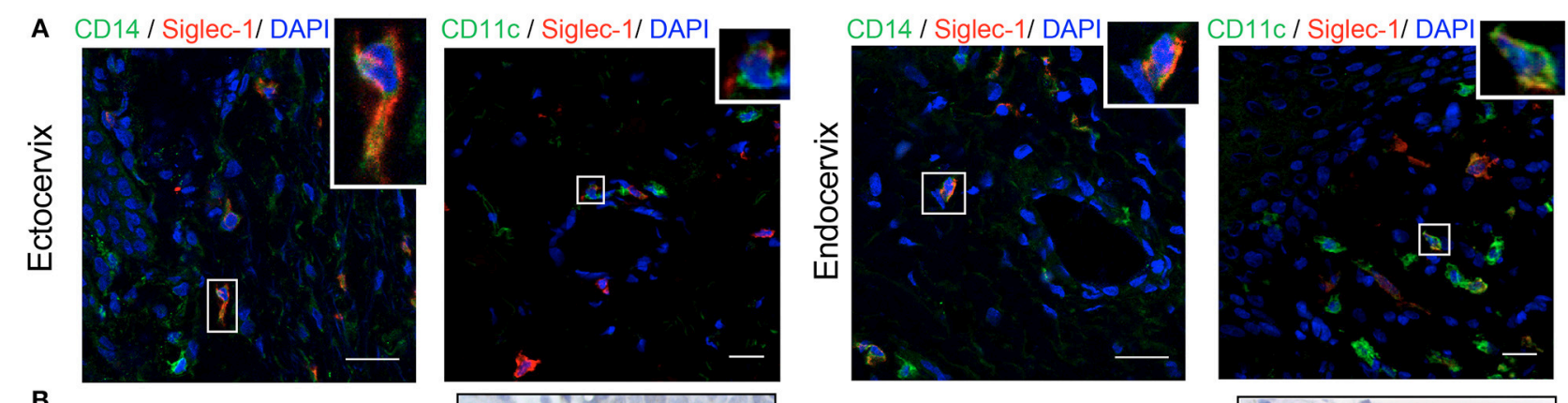

B

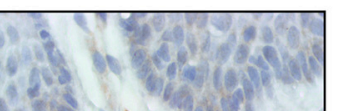

$$
\text { . }
$$

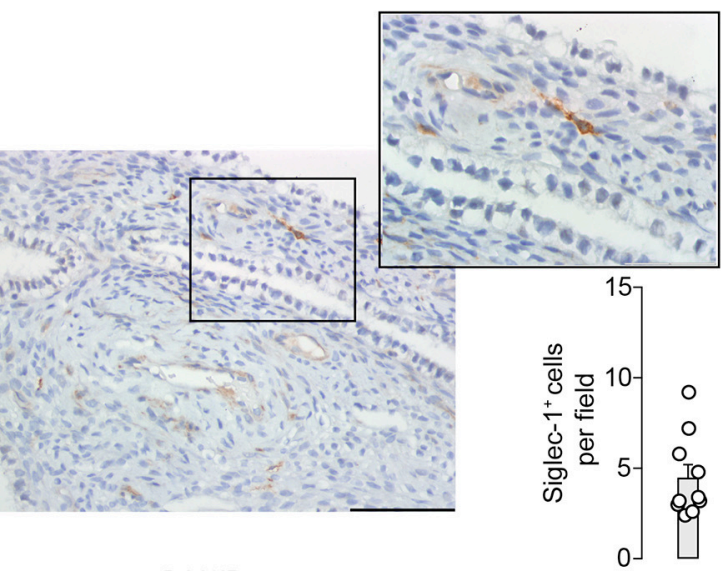

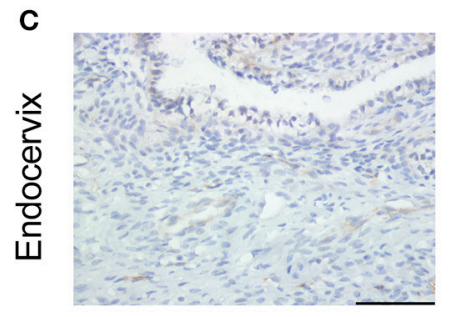

Inflammation:

Low

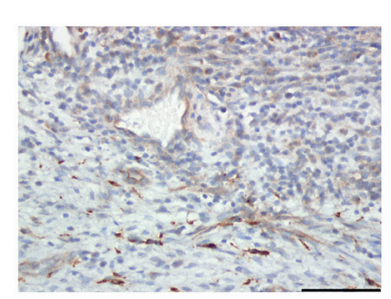

High

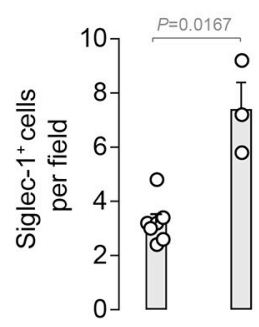

Inflammation: Low High

FIGURE 2 | Siglec-1 ${ }^{+}$cells accumulate in the submucosa of the ectocervix and endocervix. (A) Representative immunofluorescent stainings on four ectocervix and endocervix of CD14 (AF488) and Siglec-1 (AF647), or CD11c (AF488) and Siglec-1 (AF647). Scale bars $20 \mu \mathrm{m}$. (B) Representative images of Siglec-1 immunostaining (40x) on 10 ectocervix and endocervix. Scale bars $100 \mu \mathrm{m}$. Insets show Siglec- $1^{+}$cells magnification (100x). Bar graph shows the mean values and SEM of Siglec- $1^{+}$cells per field counted in 5 consecutive fields. (C) Representative images of Siglec- 1 immunostaining (40x) on 10 endocervix displaying a low and high grade of inflammation. Scale bars $100 \mu \mathrm{m}$. Bar graph shows the mean values and SEM of Siglec-1 ${ }^{+}$cells per field counted in 5 consecutive fields of 10 endocervix with different inflammation grades. Statistical differences were assessed with a Mann-Whitney test.

\section{DCs From Cervical Mucosa Mediate Viral Uptake via Siglec-1 and Are Detected in vivo}

To investigate whether Siglec- $1^{+}$cervical myeloid cells could capture and store HIV-1 via the interaction with this particular I-type lectin receptor, we next pulsed cervical cell suspensions processed immediately after prescribed surgery with fluorescent viruses. Cells were incubated with HIV-1 Virus-Like Particles (HIV-1 $1_{\text {Gag-eGFP }}$ VLPs), which lack the viral envelope glycoprotein but carry sialyllactose-containing gangliosides recognized by Siglec-1 receptor and recapitulate HIV-1 uptake results obtained with wild type viruses in myeloid cells $(30,31)$. After VLP exposure, cervical mononuclear cells were extensively washed and assessed by flow cytometry. Among the single-live $\mathrm{CD}_{4} 5^{+}$myeloid $\mathrm{HLA}-\mathrm{DR}^{+}$fraction, a mean of 
TABLE 1 | Clinical data associated to cervical tissues where Siglec-1 was quantified by IHQ.

\begin{tabular}{|c|c|c|c|c|c|c|}
\hline Patient & $\begin{array}{l}\text { Siglec-1 }-1^{+} \text {cells per field } \\
\text { at the Ectocervix }\end{array}$ & $\begin{array}{l}\text { Siglec- }-1^{+} \text {cells per field } \\
\text { at the Endocervix }\end{array}$ & Age (yr) & Indication for surgery & HIV status & Viral Load (copies/ml) \\
\hline 1 & 9,6 & 2,6 & 52 & Prolapse & - & NA \\
\hline 2 & 2,3 & 3,4 & 53 & Prolapse & - & NA \\
\hline 3 & 4,2 & $7,2^{*}$ & 45 & Prolapse & - & NA \\
\hline 4 & 13,8 & $9,2^{\star}$ & 52 & Prolapse & - & NA \\
\hline 5 & 3,6 & $5,8^{\star}$ & 60 & Prolapse & - & NA \\
\hline 6 & 8,8 & 4,8 & 59 & Unknown & + & $<50(\mathrm{ART})$ \\
\hline 7 & 6,4 & 2,4 & 45 & Prolapse & + & $<50(\mathrm{ART})$ \\
\hline 8 & 11,6 & 3,2 & 57 & Cystocele & + & 140 (ART) \\
\hline 9 & 5,4 & 3 & 41 & Uterine fibroids & + & 400 Controller (naïve) \\
\hline 10 & 8 & 3,2 & 52 & Prolapse + Cystocele & + & 1.164 (naïve) \\
\hline
\end{tabular}

Higher levels of inflammation were observed in these tissues*

11.8 and $3.6 \%$ of cells expressed Siglec- 1 in the ectocervix and endocervix (blue gate and bar graph, Figure 3A), while a 14.1 and $7 \%$ of cells captured HIV-1 $1_{\text {Gag-eGFP VLPs (green gate }}$ and bar graph, Figure 3B). Moreover, cells not capturing VLPs lacked Siglec-1 expression (gray gate, Figure 3C), while cells that captured viruses were predominantly Siglec- $1^{+}$in most of the tissues (purple gate and bar graph, Figure 3D). Viral uptake by Siglec- $1^{+}$cells was further confirmed by Amnis-imaging FACS technology, which allowed microscope inspection of acquired cells and screening of Siglec-1/VLP co-localization. Amnis viral capture assays revealed that fluorescent $\mathrm{HIV}-1_{\mathrm{Gag}-\mathrm{eGFP}}$ VLP localized with Siglec-1 within a virus-containing compartment (Figure 3E), resembling to the sac-like structures previously described in monocyte-derived DCs and activated tonsillar myeloid cells $(19,31)$. As HIV-1 $1_{\text {Gag-eGFP VLP had no viral }}$ envelope glycoprotein, observed uptake could only rely on Siglec-1 recognition of sialylated gangliosides anchored on viral membranes $(26,30)$. Thus, Siglec- $1^{+}$myeloid cells found in the ectocervix and endocervix capture $\mathrm{HIV}-1_{\mathrm{Gag}-\mathrm{eGFP}}$ VLP in a virus-containing compartment via Siglec-1 recognition of viral membrane gangliosides.

To further assess if Siglec- ${ }^{+}$cervical cells are capable of capturing wild type HIV-1 during the natural course of infection, we next investigated the cervical biopsy of a viremic $\mathrm{HIV}-1^{+}$patient by immunostaining. Confocal microscopy analysis revealed that distinct Siglec- $1^{+}$cells found in the cervical submucosa harbored viral p24 antigens (Figure 3F). Three-dimensional z-stack reconstructions of Siglec- $1^{+}$cells from distinct tissue areas showed viruscontaining compartments that were different from the p24 staining of productively infected cells lacking Siglec1 expression (Figure 3G and Movie 1). Thus, Siglec- $1^{+}$ cervical cells can trap viruses throughout the course of HIV-1 infection in vivo.

\section{pDCs Exposed to HIV-1 Induce Siglec-1 Expression on DCs via IFN $\alpha$ Secretion}

Although the basal expression of Siglec-1 on cervical DCs already allows viral uptake, the level of expression of this typeI interferon inducible receptor (21) correlates with viral capture and transmission efficiency of DCs (20). Hence, right after HIV-1 infection and once the antiviral type-I IFN responses are triggered, we hypothesized that IFN $\alpha$ could up-regulate Siglec-1 expression on cervical DCs and enhance their viral uptake capacity. In the cervical mucosa, resident myeloid cells quickly induce type-I IFN responses after HIV/SIV infection (32). Moreover, plasmacytoid dendritic cells (pDCs), the most potent producers of IFN $\alpha$, are soon recruited to the site of initial retroviral infection (33). Thus, we next assessed if IFN $\alpha$ secreted by HIV-1-exposed pDCs could trigger Siglec-1 expression on DCs, mimicking early events of HIV-1 pathogenesis once infection has been established and type-I IFN antiviral immunity is mounted. Blood derived pDCs were cultured alone, cocultured with an uninfected T cell line or with an HIV-1-infected $\mathrm{T}$ cell line that chronically produces $\mathrm{R} 5$-tropic $\mathrm{BaL}$ viruses in the presence or absence of anti-CD4 or isotype monoclonal antibodies (mAb). HIV-1-exposed pDCs released higher IFN $\alpha$ compared to non-exposed pDCs (Figure 4A), while blockage of pDC infection with a $\mathrm{mAb}$ against $\mathrm{CD} 4$ reduced $\mathrm{IFN} \alpha$ secretion compared to an isotype control (Figure 4A). Accordingly, Siglec1 expression was increased on monocyte-derived DCs incubated with supernatants from HIV-1-exposed pDCs as compared to supernatants from uninfected pDCs (Figure 4B), and further inhibited by an anti-CD4 mAb (Figure 4B). Thus, HIV-1 sensing via viral fusion on $\mathrm{pDC}$ induced IFN $\alpha$ secretion that triggered Siglec-1 expression on monocyte-derived DCs as potently as recombinant IFN $\alpha$ (Figure 4C), and was specifically inhibited by the type-I interferon blocking receptor B18R (Figure 4C). Moreover, HIV-1-exposed pDCs derived from pre-menopause women released significantly higher amount of IFN $\alpha$ than pDCs derived from men (Figure 4D). We also induced Siglec1 expression with equal amounts of recombinant IFN $\alpha$ on monocyte-derived DCs from men and women and determined the absolute number of Siglec-1 antibody binding sites per cell (Figure 4E). Under these experimental conditions, however, DCs derived from women did not significantly express higher amounts of Siglec-1 than DCs derived from men (Figure 4E). All together, these results highlight how upon HIV-1 infection, pDC accumulation in the female genital tract could lead to an increased antiviral IFN $\alpha$ secretion that could limit viral infection 

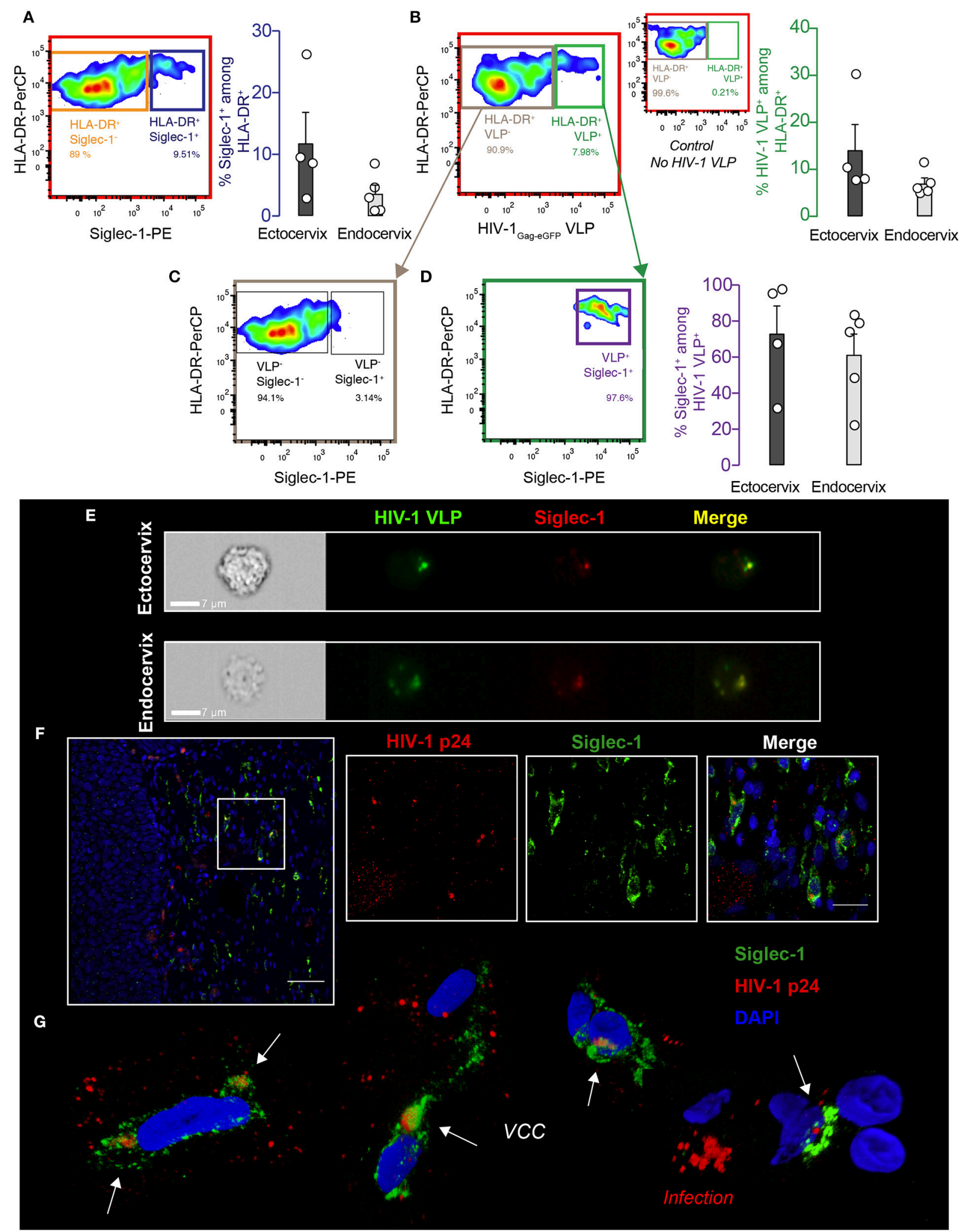

FIGURE 3 | DCs from cervical mucosa mediate viral uptake via Siglec-1 and are detected in vivo. (A) Cervical mononuclear cells isolated from the ectocervix and endocervix of benign hysterectomies were pulsed with VLPs for $18 \mathrm{~h}$ at $37^{\circ} \mathrm{C}$, extensively washed, labeled with the indicated mAbs and assessed by FACS. Colored 
FIGURE 3 | gates and arrows indicate populations analyzed, and corresponding matching colors are used to identify bar graphs showing frequencies of those populations. Representative dot plot and frequency of $\mathrm{HLA}-\mathrm{DR}^{+}$and Siglec-1 $1^{+}$cells on hematopoietic cervical cells. (B) Representative dot plot and frequency of cells capturing HIV-1 Gag-eGFP VLPs among the myeloid HLA-DR ${ }^{+}$fraction. Smaller dot plot in between depicts the control without VLPs. (C) Representative dot plot showing reduced expression of Siglec-1 in the myeloid HLA-DR ${ }^{+}$cells not capturing HIV-1 Gag-eGFP VLPs. (D) Representative dot plot of Siglec- $1^{+}$cells among the cells capturing HIV-1 Gag-eGFP VLPs. Bar graphs show mean values and SEM from the ectocervix and endocervix of 4 to 5 donors. (E) Images of Siglec-1 ${ }^{+}$cervical cells pulsed and labeled as in (A). Cells were acquired by Amnis-imaging FACS, and showed green fluorescent HIV-1 Gag-eGFP VLPS accumulation within a sac-like virus-containing compartment enriched in Siglec-1 (labeled in red). (F) Paraffin-embedded cervical tissue from one viremic HIV-infected woman stained for HIV-1 p24 antigen (labeled in red), Siglec-1 (in green), and nucleus (in blue). Scale bar $50 \mu \mathrm{m}$. (Inset panels) zoom in of squared region with distinct fluorescences (scale bar $20 \mu \mathrm{m})$. (G) 3D volumetric $x-y-z$ data fields reconstruction of Siglec-1+ cells from four distinct areas of the cervical tissue of the viremic HIV-infected woman. Opacity representation of DAPI stained nuclei and fluorescence of the sac-like virus-containing compartment (VCC; white arrows). Right bottom image displays a characteristic cell pattern with p24+ dots reflecting viral production (Infection).

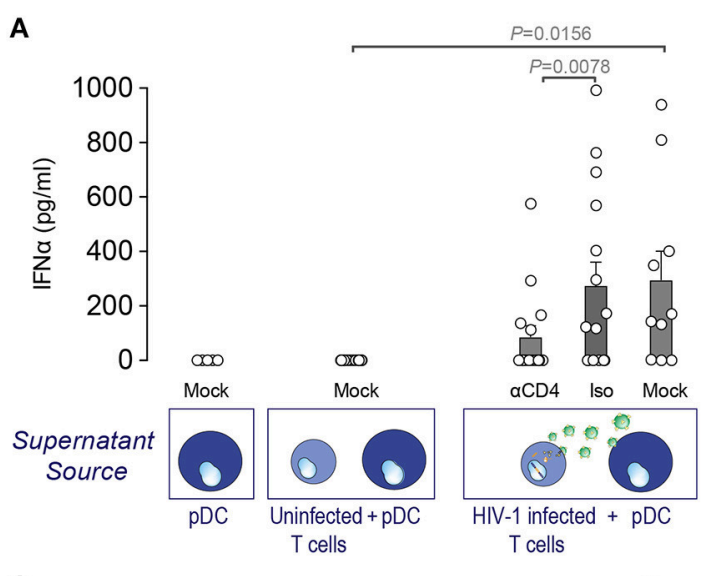

C

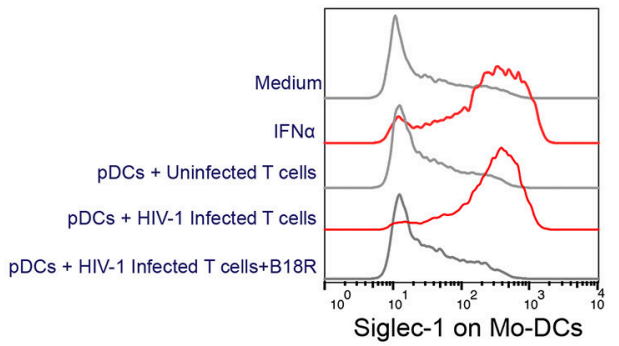

D
B
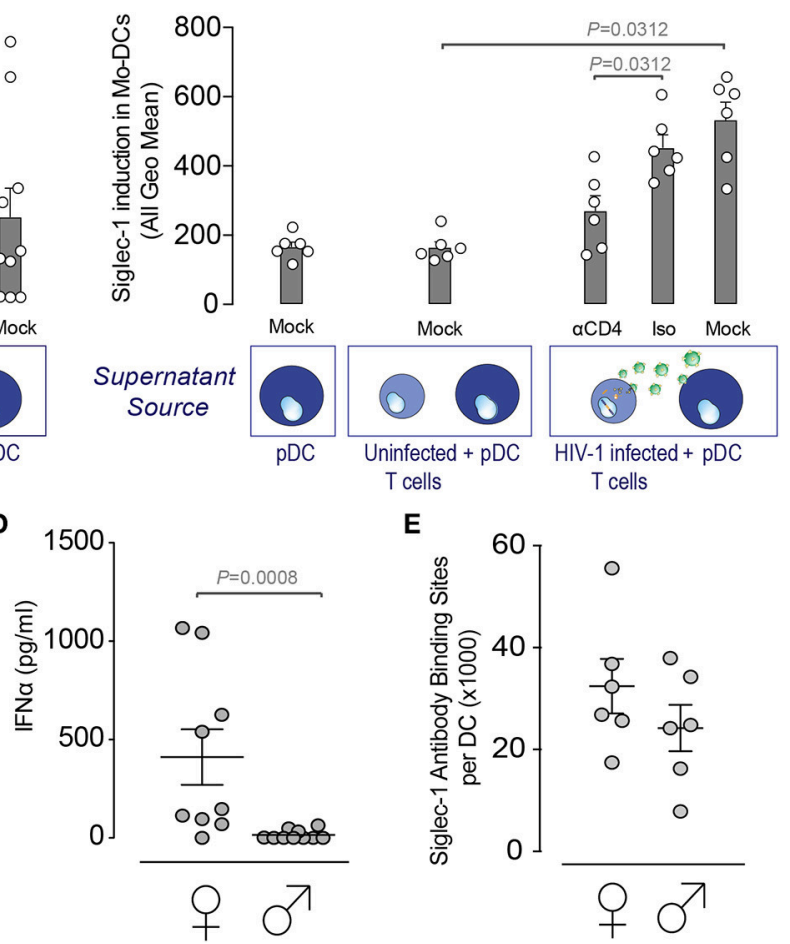

E

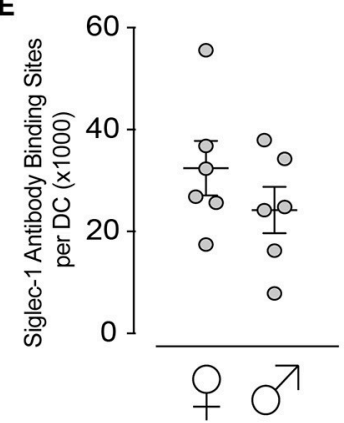

FIGURE 4 | pDCs exposed to HIV-1 induce Siglec-1 expression on DCs via IFN $\alpha$ secretion. (A) IFN $\alpha$ release measured by ELISA on supernatants from blood derived pDCs co-cultured $24 \mathrm{~h}$ alone, with an uninfected MOLT CD4 ${ }^{+} \mathrm{T}$ cell line or an HIV-1 infected MOLT CD4 ${ }^{+} \mathrm{T}$ cell line that chronically produces R5-tropic BaL viruses in the presence or absence of $10 \mu \mathrm{g} / \mathrm{ml}$ of an anti-CD4 or an isotype mAb. Bar graph shows mean values and SEM from at least 6 donors and 3 independent experiments. Statistical differences were assessed with a Wilcoxon matched-pairs signed rank test. (B) Induction of Siglec-1 on monocyte-derived DCs incubated with supernatants isolated from pDCs co-cultured as in (A) and assessed by FACS. (C) Representative histograms of Siglec-1 expression on monocyte-derived DCs exposed to medium, recombinant IFN $\alpha$, supernatants from uninfected pDCs, supernatants from HIV-1-exposed pDCs on mock treated DCs or on DCs previously incubated with the type-I interferon blocking receptor B18R. (D) IFN $\alpha$ release measured by ELISA on supernatants of pDCs isolated from women or men and co-cultured $24 \mathrm{~h}$ with an HIV-1 infected MOLT CD4 ${ }^{+} \mathrm{T}$ cell line. Bar graph shows mean values and SEM from 19 donors and 4 independent experiments. Statistical differences were assessed with a Mann-Whitney test. (E) Quantification of Siglec-1 expression levels on monocyte-derived DCs from men and women assessed by FACS. Bar graph shows mean values and SEM from 12 donors and 3 independent experiments. Prentice Rank Sum Test was used to assess statistical differences, which did not reach statistical significance $(P=0.073)$.

initially, but also promote viral capture of cervical myeloid cells via Siglec-1 induction.

\section{IFN $\alpha$ Enhances Viral Capture and Trans-infection on Siglec-1+ Cervical DCs} We next investigated if IFN $\alpha$ could trigger Siglec-1 expression on cervical myeloid cells and enhance their Siglec-1-mediated viral capture capacity. Small pieces of ectocervix or endocervix were cultured overnight (34), in the presence or absence of increasing concentrations of IFN $\alpha$ and analyzed by flow cytometry after enzymatic digestion. IFN $\alpha$ induced a dose-response increase in the percentage of Siglec- $1^{+}$cells among the myeloid HLA$\mathrm{DR}^{+} \mathrm{CD}_{14}{ }^{+} \mathrm{CD} 11 \mathrm{c}^{+}$DC fraction (Figure 5A). Moreover, on cellular suspensions obtained from cervical tissues immediately 
processed after surgery, IFN $\alpha$ treatment also increased the percentage of Siglec- $1^{+}$cells (Figure 5B). This effect was more prominent in the endocervix, where basal expression of Siglec1 was lower (Figures 1D, 5B). Accordingly, IFN $\alpha$ treatment increased the percentage of cells capturing HIV-1 $1_{\text {Gag-eGFP VLP }}$ among the myeloid HLA-DR ${ }^{+} \mathrm{CD} 14^{+} \mathrm{CD} 11 \mathrm{c}^{+} \mathrm{DC}$ population, especially at the endocervix (Figure 5C). Thus, endocervical myeloid cells could mediate trans-infection more potently once antiviral type I IFN responses are mounted and Siglec-1 expression is triggered on DCs.

Our results suggested that $\alpha$-Siglec- 1 mAbs could offer protection against HIV-1 uptake and prevent dissemination mediated by cervical DCs. We therefore pre-incubated cells from the ectocervix and endocervix with an $\alpha$-Siglec- $1 \mathrm{mAb}$ or isotype control before viral exposure (Figure 5D). While isotype control had no inhibitory effect, pre-treatment with $\alpha$-Siglec- $1 \mathrm{mAbs}$ led to a reduction of HIV-1 $1_{\text {Gag-eGFP }}$ VLP uptake even after IFN $\alpha$ treatment (Figure 5D). Moreover, this blocking effect was further confirmed using a wild type R5-tropic $\mathrm{HIV}-1_{\mathrm{NFN}-\mathrm{SX}}$ to pulse mock treated or IFN $\alpha$-treated $\mathrm{CD}^{-} \mathrm{HLA}^{-} \mathrm{DR}^{+}$cervical DCs, which were sorted and co-cultured with a reporter $\mathrm{CD}^{+}$cell line to measure viral transfer via trans-infection (Figure 5E). Of note, at the steady state, the expression of Siglec-1 on these cells is shown on Figure 1D. In seven independent cervicovaginal tissues, we consistently observed a significant decrease in the levels of HIV-1 transmitted in the $\alpha$-Siglec- $1 \mathrm{mAb}$ treated cells compared to the isotype control, which accounted for blocking a mean of $70 \%$ of the transferred infectivity by myeloid cells. Thus, at the basal state but also upon Siglec-1 induction by IFN $\alpha$, the $\alpha$-Siglec- $1 \mathrm{mAb}$ could most likely block viral binding and uptake, preventing subsequent viral transmission from myeloid cells to target cells. These results highlight that specific inhibitors against Siglec- 1 can halt viral transfer and dispersion mediated by Siglec $-1^{+}$cervical DCs.

\section{DISCUSSION}

A preventative strategy aimed at protecting against HIV infection must block several steps during the earliest stages of infection, avoiding not only the productive infection of primary target cells, but also the viral dissemination toward distal tissues. In both scenarios, antigen-presenting cells residing in different compartments of the female genital mucosa may play a prominent role $(7,9,24,35)$. DC-T cell conjugates represent an optimal milieu for productive HIV infection, which may boost initial viral replication of $\mathrm{CD}^{+} \mathrm{T}$ cells $(10,36)$. Moreover, uninfected DCs could promote HIV dissemination to draining lymph nodes after mucosal challenge $(8,9)$. Yet, the precise molecular mechanism mediating these processes remained unexplored in the cervicovaginal tissue.

Here we have shown the ability of Siglec- 1 to mediate viral capture and transmission to target cells on a population of cervical myeloid cells expressing HLA-DR, CD11c, CD14, and CD11b, all classical markers known to be present on DCs of the submucosa at the lower female genital tract $(18,28,29,37)$. Our findings concur with prior studies where the migratory
$\mathrm{CD}^{-}{ }^{-}$HLA-DR ${ }^{+}$fraction or the cervicovaginal CD11c ${ }^{+}$DCs were found to be the myeloid cell subset that preferentially captured and transported HIV-1 out of the cervicovaginal mucosa $(5,16,17)$. Nevertheless, we now show that on DCs of the ectocervix and endocervix, alternative receptors beyond DCSIGN operate in HIV-1 viral uptake and transfer, as previously reported for monocyte-derived DCs $(13,15,38-43)$. Our results provide a plausible mechanism for previous reports where the predominant cervical myeloid cell population that captured HIV1 was found to be DC-SIGN negative (18), or where there was a lack of inhibition of neutralizing antibodies against DC-SIGN on viral transmission mediated by cervical myeloid cells (5). The discovery of Siglec-1 expression on myeloid cervical DCs and the capacity of Siglec- $1^{+}$cells to capture viruses in vivo help to understand how this particular receptor can facilitate boosting of HIV-1 replication and dissemination from the genital mucosa to the corresponding draining lymph nodes in the absence of DC productive infection.

Baseline levels of Siglec-1 on myeloid cells in the lamina propria of all cervical tissues examined herein already allowed viral uptake, demonstrating that Siglec-1 could act as a viral attachment factor even in the absence of prior viral infection. However, as tissues with a high level of inflammatory infiltrate showed an increased number in Siglec-1 ${ }^{+}$cells, ongoing inflammatory events triggered upon infection could magnify Siglec-1 mediated HIV-1 uptake and trans-infection. Indeed, in a cervical biopsy of an HIV-1 viremic woman, we found Siglec-1 ${ }^{+}$ cells with HIV-1-containing compartments, demonstrating that these cells actually trap viruses and form these compartments in vivo.

In the female genital tract, type I IFN responses from tissue resident cells represent a potent first-line of defense against many pathogens, including lentiviruses (44-47). Soon after infection, recruited $\mathrm{pDC}$ sensing incoming viruses will strongly contribute to IFN $\alpha$ secretion (33). Here we confirmed that HIV-1 fusion on pDCs induced IFN $\alpha$ secretion $(48,49)$ and that this mechanism, which is subjected to hormonal regulation (50), was enhanced in $\mathrm{pDC}$ derived from pre-menopausic women. However, gender did not affect the IFN $\alpha$ response that triggered Siglec- 1 induction on DCs, as it had been previously reported for other interferonstimulated genes during chronic HIV-1 infection (51). Further, we demonstrated that $\mathrm{CD} 14^{+} \mathrm{CD} 11 \mathrm{c}^{+}$DCs up-regulate Siglec1 expression in a dose response manner after IFN $\alpha$ stimulation of the cervical tissue, especially at the endocervix. In contrast, higher basal expression of Siglec-1 was found on ectocervical myeloid cells at the steady state. These data suggest that while pre-existing basal immune activation at the ectocervix could already favor Siglec-1 capture of early invading viruses, endocervical cells will most likely mediate viral uptake at later time points, once antiviral type I IFN responses are mounted and Siglec-1 expression is boosted on DCs. Indeed, this could explain why we only observed an increased number of Siglec- $1^{+}$cells on biopsies from the endocervix that had a high inflammatory score. Overall, detection of Siglec-1 on cervical DCs contributes to understand why the IFN system is not more effective against HIV-1 despite its substantial up-regulation early upon infection $(4,33,52)$. Similarly, it may also explain why treatments inducing 
A

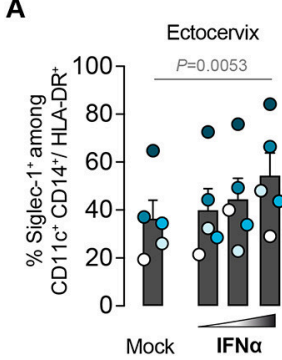

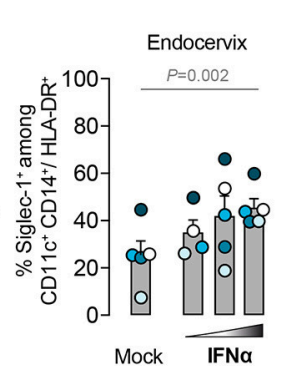

B

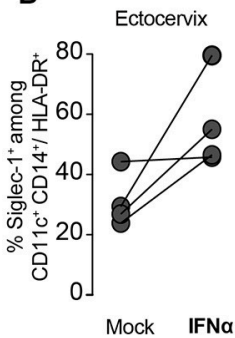

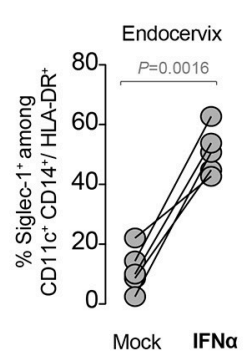

C
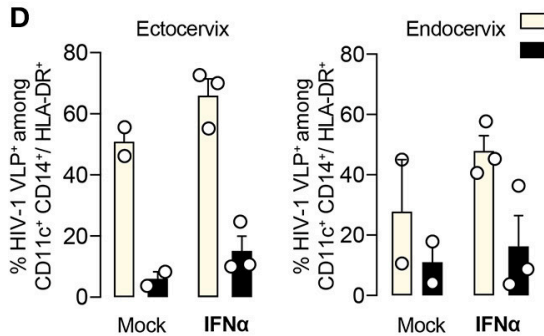

Isotype

a-Siglec-1 mAb

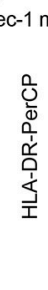

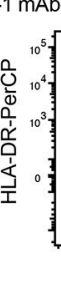

Isotype

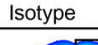

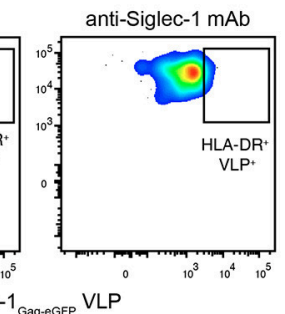

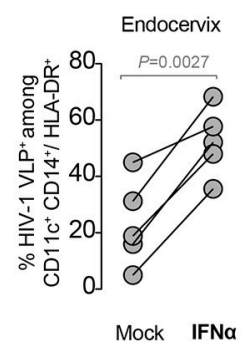

Mock IFNa Mock IFNa
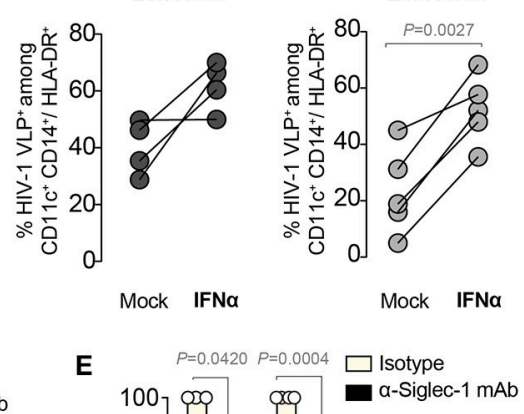

FIGURE 5 | IFN $\alpha$ enhances viral capture and trans-infection on Siglec-1+ cervical DCs. (A) Percentage of Siglec- ${ }^{+}$DCs $^{+}$within the myeloid HLA-DR ${ }^{+}$CD14 ${ }^{+}$

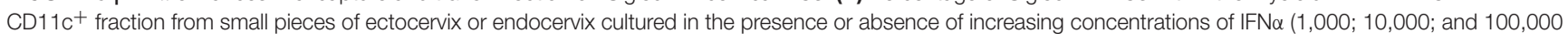
$\mathrm{IU} / \mathrm{ml}$ ) and assessed by FACS as in Figure 3. Bar graph shows mean values and SEM from 5 donors and 4 independent experiments. Colors depict each particular donor. Statistical differences were assessed with a one-way repeated measures ANOVA test. (B) Percentage of Siglec-1 ${ }^{+}$DCs within the myeloid HLA-DR ${ }^{+}$CD14 ${ }^{+}$ $\mathrm{CD}_{11 \mathrm{C}^{+}}$fraction from cellular suspensions obtained from tissue digestion and cultured in the presence or absence of IFN $\alpha$. Statistical differences were assessed with a paired $t$-test. (C) Percentage of cells capturing HIV-1 Gag-eGFP VLPs among the myeloid HLA-DR ${ }^{+}$CD14 $^{+}$CD11C $^{+}$fraction from cellular suspensions obtained from ectocervix or endocervix digestion and cultured in the presence or absence of IFN $\alpha$. Statistical differences were assessed with a paired $t$-test. (D) Percentage of cells capturing HIV-1 Gag-eGFP VLPs as in (C) on cells that had been previously pre-incubated with $20 \mu \mathrm{g} / \mathrm{ml}$ of 7D2 anti-Siglec-1 mAb or isotype control. Bar graph shows mean values and SEM from 2-3 donors. Dot plots showing representative inhibition are also depicted. (E) Relative R5 tropic HIV-1 NFN-SX transmission to $\mathrm{CD}^{+}$target cells from cervical CD45 ${ }^{+} \mathrm{CD} 3^{-} \mathrm{CD} 19^{-} \mathrm{HLA}_{-\mathrm{DR}}^{+}$sorted cells pre-incubated with $20 \mu \mathrm{g} / \mathrm{ml}$ of isotype or anti-Siglec-1 mAbs before viral exposure. Values are normalized to isotype-treated cells (set at 100\%). Statistical differences were assessed with a one sample $t$-test. Mean values and SEM from two experiments include cells from 3 or 4 donors.

pDC recruitment (53) and a strong type I IFN response (54) before vaginal challenge in macaques are incapable of limiting viral infection beyond the infected mucosa and can even enhance viral replication.

As other sexually transmitted infections such as herpes virus or chlamydia infection trigger type I IFN responses in mucosal tissues via $\mathrm{pDC}$ recruitment and/or bacterial lipopolysaccharide exposure $(55,56)$, it would be important to explore the role of Siglec-1 in favoring HIV-1 acquisition, replication and dissemination in women with pre-existing sexually transmitted infections (2). Moreover, since inflammatory CD14 ${ }^{+} \mathrm{CD}_{11 c^{+}}$ DCs are known to induce Th17 T-cell differentiation (57), and these are the preferential targets of viral infection in the cervix right after retroviral invasion (58), it would also be critical to evaluate the role of this Siglec- $1^{+}$DC subset on susceptibility to HIV-1 infection.

In summary, myeloid DCs expressing a key molecule involved in HIV-1 trans-infection, namely Siglec-1, are found in the cervical tissues of women in the basal state. IFN $\alpha$-treated myeloid DCs up-regulate Siglec-1 expression, which increases viral capture and trans-infection, providing an explanation of how the virus may succeed in an otherwise antiviral environment. We propose that Siglec- $1^{+}$cervical DCs may facilitate HIV-1 transfer to bystander $\mathrm{CD}^{+} \mathrm{T}$ cells and favor the nascent infection within the cervical mucosa, but also facilitate early dissemination to secondary lymphoid tissues. These findings highlight the importance of including Siglec-1 inhibitors along with potent antiretroviral agents in forthcoming microbicidal strategies, to stop not only the productive cellular infection in the cervix, but also the systemic viral dissemination from the female genital tract.

\section{METHODS}

\section{Cervical Tissue Digestion and Immunophenotype}

Human cervical tissue was obtained from women (age range 39-82 years) undergoing hysterectomy for non-neoplasic indication at either HUGTiP or Hospital Municipal de Badalona. After confirmation of healthy tissue status by the Pathology Service, a piece from ectocervix and endocervix separated by anatomical localization was delivered to the laboratory in tissue media [RPMI 1640 supplemented with $15 \%$ FBS, $500 \mathrm{U} / \mathrm{mL}$ penicillin, $500 \mu \mathrm{g} / \mathrm{mL}$ streptomycin, $2.5 \mu \mathrm{g} / \mathrm{mL}$ Fungizone (Life Technologies), $50 \mu \mathrm{g} / \mathrm{mL}$ gentamicin, MEMnon essential aminoacids (Gibco) and $1 \mathrm{mM}$ MEM-sodium pyruvate (Gibco)]. Tissue was processed within the next $24 \mathrm{~h}$ after surgery. The mucosal epithelium and the underlying 
stroma of both ectocervix and endocervix were separated from muscular tissue and dissected into approximately $8-\mathrm{mm}^{3}$ blocks. Depending on the experiment, tissue blocks were cultured, digested or included in optimal cutting temperature compound for immunofluorescence as previously described (34).

For tissue digestion, five to eight pieces from ectocervix or endocervix were separately placed into $1.5 \mathrm{ml}$-tubes containing 5 $\mathrm{mg} / \mathrm{ml}$ collagenase IV (Invitrogen) in RPMI 1640 supplemented with $5 \%$ fetal bovine serum (FBS, Gibco). Tubes were shaked at $400 \mathrm{rpm}$ at $37^{\circ} \mathrm{C}$ for $30 \mathrm{~min}$. After enzymatic digestion, tissue blocks were dissociated manually with a disposable pellet pestle in two series of 20 rotations while pulling it up and down. The suspension was filtered through a $70 \mu \mathrm{m}$ cell strainer (SPL Life Sciences), and cells were collected at $16^{\circ} \mathrm{C}$ after washing with PBS. Cells were then stained with Live/Dead Aqua (Invitrogen) for $30 \mathrm{~min}$ at RT. Pellet was suspended in staining buffer (1\% mouse serum, $1 \%$ goat serum in PBS) and stained with CD14-V450 (MØP9), CD11c-PE-Cy7 (B-ly6), HLA-DR-PerCPCy5.5 (G46-6), (all from BD Biosciences), CD3-eVolve 655 (OKT3) (eBiosciences), CD45-Alexa Fluor 700 (Hl30), CD11bFiTC (M1/70), Siglec-1-PE (7-239) (all from BioLegend). Mouse IgG1-PE (BioLegend) was used as isotype control. Cells were acquired using a BD LSRFortessa SORP flow cytometer (Flow Cytometry Platform, IGTP) and analyzed with FlowJo vX.0.7 software (TreeStar).

\section{Immunofluorescence}

Cervical $5-\mu \mathrm{m}$ cryosections were dried at RT, fixed in $3.7 \%$ formaldehyde (Sigma Aldrich) diluted in PHEM buffer as previously described in (34), permeated with $0.2 \%$ Triton X100 (Sigma Aldrich) in PHEM buffer and blocked with $0.2 \%$ cold fish gelatin (Sigma Aldrich), 0.1\% Triton X-100 and 10\% normal goat serum (Gibco) diluted in PBS. Sections were first incubated with the following primary mAbs: mouse anti-Siglec1 7-239 Ab (Abcam), rabbit anti-CD11c EP1347Y Ab (Abcam) or rabbit anti-CD14 EPR3653 Ab (Abcam). Samples were then washed extensively with PBS and incubated with the secondary mAbs Alexa 488-conjugated donkey anti-rabbit or Alexa 647conjugated donkey anti-mouse IgG (Jackson ImmunoResearch). Sections were covered with mounting medium (ProLong ${ }^{\mathrm{TM}}$ Gold Antifade Mountant with DAPI, Life Technologies, Invitrogen) and a coverslip. Images were obtained by confocal microscopy using a Zeiss LSM 710 microscope and the Zen Blue Image acquisition software.

\section{Immunohistochemistry}

Ten cervical formalin-fixed, paraffin-embedded samples from the Pathology Department of HUGTiP were analyzed. Of note, we chose samples from five HIV-1 infected and five seronegative women, but results were equivalent regardless of the HIV status. Immunohistochemical stains were performed using a Ventana Benchmark Ultra (Ventana Medical Systems) in accordance with the manufacturer's protocol, with standard antigen retrieval $(\mathrm{pH}$ 9.0; Ventana) and the mAb against $\alpha$-Siglec-1 (clone SP213, LS Biosciences, dilution 1/100) for $12 \mathrm{~min}$. A pathologist carried out a blind quantification of Siglec- $1^{+}$cells and images were captured using a DP71 digital camera (Olympus, Center Valley,
PA, USA) attached to a BX41 microscope (Olympus). Siglec$1^{+}$cells in five consecutive fields in the subepithelial area were counted for ectocervix and endocervix separately. Tissues where a significant inflammatory infiltrate was detected were considered as highly inflamed.

\section{Cell Lines}

HEK-293T cells obtained from ATCC (CRL-11268) and TZMbl (obtained through the US National Institutes of Health [NIH] AIDS Research and Reference Reagent Program) were maintained in Dulbecco's Modified Eagle Medium (DMEM). The human $\mathrm{T}$ cell lines MOLT CD4 ${ }^{+}$uninfected and MOLT CD4 ${ }^{+}$ $\mathrm{HIV}-1_{\mathrm{BaL}}$ infected have been described elsewhere (59) and were grown in RPMI. All media contained 10\% FBS, $100 \mathrm{U} / \mathrm{ml}$ of penicillin and $100 \mu \mathrm{g} / \mathrm{ml}$ of streptomycin (all from Invitrogen).

\section{HIV-1 Gag-eGFP VLP and HIV-1 Generation}

Fluorescent HIV-1 virus-like particles $\left(\mathrm{HIV}-1_{\mathrm{Gag}-\mathrm{eGFP}} \mathrm{VLP}\right)$ were generated transfecting HEK-293T cells with plasmid pGag-eGFP obtained from the NIH AIDS Research and Reference Reagent Program. Replication-competent HIV-1 stock was generated by transfecting the proviral construct NFN$\mathrm{SX}$, an $\mathrm{HIV}-1_{\mathrm{NL} 43}$ provirus that expresses the HIV-1 $1_{\text {JRFL }}$ envelope glycoprotein (kindly provided by W. O’Brien). Thirty micrograms of plasmid DNA were added to cells in T75 flasks, and transfection was performed using a calcium phosphate kit (CalPhos, Clontech). Forty-eight hours post-transfection, supernatants were harvested, filtered (Millex-HV, $0.45 \mu \mathrm{m}$; Millipore) and frozen at $-80^{\circ} \mathrm{C}$ until use. The p $24^{\mathrm{Gag}}$ content of the VLP and HIV-1 stock was determined by ELISA (PerkinElmer). TCID $_{50}$ or $50 \%$ tissue culture infective doses of $\mathrm{HIV}_{\mathrm{NFN}-\mathrm{SX}}$-infection used for trans-infection assays were determined by end-point dilution culture on the cell line TZM-bl, which contains an HIV long terminal repeat linked to a luciferase reporter gene.

\section{VLP Uptake Assays}

$1 \times 10^{6}$ digested ectocervical and endocervical cells were preincubated for $15 \mathrm{~min}$ at RT with $20 \mu \mathrm{g} / \mathrm{ml}$ of an anti-Siglec- $1 \mathrm{mAb}$ (7D2) (Abcam), a murine IgG1 $\kappa$ isotype control (BD Pharmigen) or left untreated. Cells were pulsed overnight with 2.7- $20 \mathrm{ng}$ p $24^{\mathrm{Gag}} \mathrm{HIV}-1_{\mathrm{Gag}-\mathrm{eGFP}} \mathrm{VLP}$ at $37^{\circ} \mathrm{C}$ in a $5 \% \mathrm{CO}_{2}$ incubator in the presence or absence of $1,000 \mathrm{IU} / \mathrm{ml}$ of recombinant Interferon$2 \alpha$ (Sigma-Aldrich) in 10\% FBS RPMI with antibiotics. After extensive washing, cells were stained as previously described and acquired using a BD LSRFortessa SORP flow cytometer (Flow Cytometry Platform, IGTP) and analyzed with FlowJo v10.3 software (TreeStar).

For imaging flow cytometer analyses, $1 \times 10^{6}$ digested ectocervical and endocervical cells were pulsed with HIV-

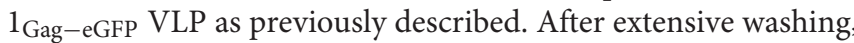
cells were resuspended in PBS with 1:250 Live/Dead Aqua (Invitrogen) and incubated for $30 \mathrm{~min}$ at RT. Cells were then fixed and permeabilized (Fix \& Perm; Invitrogen), and stained with an anti-Siglec-1-PE mAb (7-239) (BioLegend). Cells were acquired with an Amnis ImageStreamX imaging flow cytometer (Merck), and analyzed using IDEAS v6.1 software. A gradient root mean 
square or RMS value $>40$ was established as the best focus threshold, and single cells were selected in the Area vs. Aspect Ratio dot plot of the bright field channel.

\section{HIV-1 p24 Immunostaining}

A cervical formalin-fixed, paraffin-embedded sample from a viremic patient diagnosed with sexually transmitted HIV-1 infection a decade ago was obtained from the Pathology Department of the University Hospital Vall d'Hebron. The sample was collected when the patient had between 5,160 and 10,400 HIV-1 RNA copies/ml in blood. Samples were de-waxed and placed in decreasing ethanol concentrations. Heat-induced epitope retrieval was performed in EDTA buffer pH 9 (Abcam) in a water bath at $100^{\circ} \mathrm{C}$ during $10 \mathrm{~min}$. Slides were permeabilized with Tris-bufferd saline $1 \mathrm{X}$ (TBS) (Fisher scientific) with $0.1 \%$ Triton X-100 and $1 \%$ BSA (SigmaAldrich) for $10 \mathrm{~min}$. Subsequently, blocking was performed with TBS $1 \mathrm{x}$ supplemented with $10 \%$ donkey serum (Jackson Immunoresearch) and 1\% BSA for 2h. Mouse anti-p24 mAb (Kal1; Dako-Agilent) was incubated overnight at $4^{\circ} \mathrm{C}$. Later, rabbit anti-Siglec-1 mAb (SP213; Lifespan Bioscience) was incubated for $15 \mathrm{~min}$ at RT. Samples were then stained with secondary antibodies Donkey AlexaFluor 647 anti-mouse (Invitrogen) and Donkey AlexaFluor 488 anti-rabbit; counter stained with DAPI (Thermo Fisher) and mounted with Fluoromount G (eBioscience). Samples were imaged on an Olympus Spectral Confocal Microscope FV1000 using a 20x and 60x phase objective and sequential mode to separately capture the fluorescence at an image resolution of $800 \times 800$ pixels. Image $\mathrm{J}$ software was used for image processing. Alternatively, samples were acquired in z-stacks every $0.2 \mu \mathrm{m}$ on a Zeiss LSM 780 confocal inverted microscope with an apochromatic $63 \mathrm{x}$ oil $(\mathrm{NA}=1.4)$ and processed with Volocity software using the $3 \mathrm{D}$ Opacity module for reconstruction.

\section{Primary Cell Cultures}

Peripheral blood mononuclear cells (PBMCs) were obtained from buffy coats of the Banc de Sang $i$ Texits of Barcelona by Ficoll-Hypaque density gradient centrifugation (Alere Technologies AS). Plasmacytoid DCs were negatively isolated using magnetic beads from the Plasmacytoid Dendritic Cell isolation kit (Miltenyi Biotech) and immediately used for experiments. Monocytes were isolated using $\mathrm{CD}_{1}{ }^{+}$selection magnetic beads (Miltenyi Biotech) and differentiated into monocyte-derived DCs with $1,000 \mathrm{IU} / \mathrm{ml}$ of granulocytemacrophage colony-stimulating factor plus $1,000 \mathrm{IU} / \mathrm{ml}$ of Interleukin-4 (both from R\&D) during 5 days before supernatant exposure. Cells were maintained in RPMI supplemented with $10 \% \mathrm{FBS}, 100 \mathrm{U} / \mathrm{ml}$ of penicillin and $100 \mu \mathrm{g} / \mathrm{ml}$ of streptomycin.

\section{IFN $\alpha$ Release on Supernatants From pDCs and Siglec-1 Induction}

A total of $0.1 \times 10^{6} \mathrm{pDCs}$ were co-cultured with $0.1 \times 10^{6} \mathrm{HIV}$ $1_{\mathrm{BaL}}$-infected MOLT- 4 cells for $24 \mathrm{~h}$ at $37^{\circ} \mathrm{C}$. Before co-culture, some pDCs were also pre-treated with $10 \mu \mathrm{g} / \mathrm{ml}$ of anti-CD4 $\mathrm{mAb}$ (clone RPA T-4) to avoid viral fusion or with an isotype $\mathrm{mAb}$ control (both from Beckton Dickinson) for $10 \mathrm{~min}$ at RT.
As a negative control, pDCs were co-cultured with an uninfected MOLT- 4 cell line. After $24 \mathrm{~h}$ of co-culture, supernatants were collected and assessed for IFN $\alpha$ production with VeriKine Human IFN Alpha Elisa Kit (pbl Assay Science). Alternatively, supernatants from these co-cultures were transferred to $0.2 \times 10^{6}$ DCs to assess Siglec-1 induction $24 \mathrm{~h}$ later with a FACSCalibur, labeling cells with a mAb anti-Siglec-1-PE or a matched isotype$\mathrm{PE}$ control (both from AbD Serotec). Of note, these supernatants were also added to DCs that had been previously incubated with $2 \mu \mathrm{g} / \mathrm{ml}$ of carrier-free recombinant B18R protein (eBioscience) to block type I IFN receptor. DCs were also cultured in the presence of RPMI media or $1,000 \mathrm{IU} / \mathrm{ml}$ of recombinant Interferon- $2 \alpha$. The mean number of Siglec- $1 \mathrm{Ab}$ binding sites per monocyte-derived DC from men and women was obtained with a Quantibrite kit (Becton-Dickinson) as previously described (13).

\section{Cervical Tissue Stimulation With IFN $\alpha$}

After dissection of the tissue as previously described, five pieces from ectocervix or endocervix were separately placed into a 12well plate containing $1 \mathrm{ml}$ of tissue culture medium. Interferon$2 \alpha$ was added to the medium at 1,$000 ; 10,000$ or $100,000 \mathrm{IU} / \mathrm{ml}$. After $24 \mathrm{~h}$ at $37^{\circ} \mathrm{C}$ in $5 \% \mathrm{CO}_{2}$, tissue was digested and the remaining culture plate was treated with accutase (Thermo Fisher Scientific) for $30 \mathrm{~min}$ at $37^{\circ} \mathrm{C}$ to detach adherent cells. Finally, tissue and adherent cells were pooled together and stained for flow cytometry as previously described.

\section{Trans-infection Experiments}

Ectocervical and endocervical blocks from HIV-1 non-infected donors were left untreated or incubated overnight with 10,000 $\mathrm{U} / \mathrm{ml}$ of IFN $\alpha$ and $100 \mathrm{ng} / \mathrm{ml}$ of CCL19 (Mip-3 $\beta$ ). Tissue was then digested, pooled together and stained with $\mathrm{mAbs}$ as previously described to sort single $\mathrm{CD} 45^{+} \mathrm{CD} 3^{-} \mathrm{CD} 19^{-} \mathrm{HLA}_{-\mathrm{DR}}{ }^{+}$live cells by FACS. Recovered cells were pre-incubated with anti-Siglec$17 \mathrm{D} 2$ or isotype control $\mathrm{mAbs}$ for $10 \mathrm{~min}$ at RT. Cells were subsequently incubated with $185 \mathrm{ng}$ of $\mathrm{p} 24 / \mathrm{ml}$ of an R5 tropic HIV- $1_{\text {NFN-SX }}$ (with an estimated TCID $_{50}$ of 116.824 ) in the presence of $20 \mu \mathrm{g} / \mathrm{ml}$ of the indicated $\mathrm{mAbs}$ for $4 \mathrm{~h}$ at $37^{\circ} \mathrm{C}$. After extensive washes, myeloid cells were co-cultured with the reporter TZM-bl cell line at a 1:1 ratio for $48 \mathrm{~h}$. Luciferase activity was measured with Britelite plus (Perkin Elmer) in a Synergy MX luminometer (Biotek).

\section{Statistical Analysis}

Data are reported as the mean and the standard error of the mean (SEM) for each condition. We analyzed mean changes using Mann-Whitney test, Wilcoxon matched-pairs signed rank test, paired $t$-test, and one-way repeated measures ANOVA test as indicated, which were considered significant at $P<0.05$. Significant mean changes from $100 \%$ of the data normalized to percentages were assessed with a one sample $t$-test, considered significant at $P<0.05$. Gender main effect inference across multiple experiments was assessed using the Prentice Rank Sum Test, a generalized Friedman rank sum test with replicated blocked data. All analyses and figures were generated with the GraphPad Prism v7 Software and R v3.5. 


\section{ETHICS STATEMENT}

Informed written consent was obtained from all participants and the study protocols were approved by the University Hospital Germans Trias i Pujol (HUGTiP, Badalona, Spain) and the Vall d'Hebron University Hospital (HUVH, Barcelona, Spain) Clinical Research Ethics Committee (reference numbers PI-14-070 and PR (IR)294/2017). The study was undertaken in accordance with the Declaration of Helsinki and the requirements of Good Clinical Practice.

\section{AUTHOR CONTRIBUTIONS}

DP-Z, JC-P, NI-U, and MG conceived and designed the experiments. AH-G, JC, GT, JG, and AT obtained, processed, and analyzed tissues. DP-Z, JC-P, IE, SB, MP, CS-P, and VA-S performed the experiments. DP-Z, JC-P, IE, SB, MP, CS-P, JC, GT, MJB, JM-P, NI-U, and MG analyzed and interpreted the data. DP-Z, JC-P, NI-U, and MG wrote the paper.

\section{FUNDING}

JM-P and NI-U are supported by the Spanish Secretariat of State of Research, Development and Innovation through grant SAF2016-80033-R. DP-Z is supported by the Spanish Ministry of Science, Innovation and Universities and the European Regional Development Fund under agreement BES-2014-069931. JM-P and MJB are supported by the Spanish AIDS network Red Temática Cooperativa de Investigación en SIDA RD16/0025/0007. MJB is supported by the Spanish Secretariat of Science and Innovation and FEDER funds (grant SAF2015-67334-R [MINECO/FEDER]) and by the Miguel Servet program funded by the Spanish Health Institute Carlos III (CP17/00179). MG is supported by a Marie Curie Career Integration Grant (CIG) from the European Commission, grants from the Spanish

\section{REFERENCES}

1. UNAIDS. Global AIDS Update. (2016) Geneva:UNAIDS.

2. Eid SG, Mangan NE, Hertzog PJ, Mak J. Blocking HIV-1 transmission in the female reproductive tract: from microbicide development to exploring local antiviral responses. Clin Transl Immunol. (2015) 4:e43. doi: 10.1038/cti.2015.23

3. Miller CJ, Li Q, Abel K, Kim EY, Ma ZM, Wietgrefe S, et al. Propagation and dissemination of infection after vaginal transmission of simian immunodeficiency virus. J Virol. (2005) 79:9217-27. doi: 10.1128/JVI.79.14.9217-9227.2005

4. Haase AT. Targeting early infection to prevent HIV-1 mucosal transmission. Nature. (2010) 464:217-23. doi: 10.1038/nature08757

5. Hu Q, Frank I, Williams V, Santos JJ, Watts P, Griffin GE, et al. Blockade of attachment and fusion receptors inhibits HIV-1 infection of human cervical tissue. J Exp Med. (2004) 199:1065-75. doi: 10.1084/jem.20022212

6. Shattock RJ, Moore JP. Inhibiting sexual transmission of HIV-1 infection. Nat Rev Microbiol. (2003) 1:25-34. doi: 10.1038/nrmicro729

7. $\mathrm{Hu}$ J, Gardner MB, Miller CJ. Simian immunodeficiency virus rapidly penetrates the cervicovaginal mucosa after intravaginal inoculation
Ministerio de Economía y Competitividad, Instituto de Salud Carlos III (ISCIII, PI14/01235 and PI17/01470) and by the Pla estratègic de recerca $i$ innovació en salut (PERIS), from the Catalan government.

\section{ACKNOWLEDGMENTS}

We would like to thank all the patients who participated in the study. We thank M. A. Fernández and G. Requena from the Flow Cytometry Platform at the IGTP for excellent technical assistance, as well as I. Crespo from the Flow Cytometry Platform at the IDIBAPS for her excellent technical assistance on Amnis technology. For her excellent assistance, advice, and imaging processing we thank Elena Rebollo from the Advanced Fluorescence Microscopy Unit IBMB-PCB. We also would like to thank I. Lorencés and L. Pérez-Roca from the Tumor Bank of the IGTP-HUGTiP and M. MartínCéspedes from the Pathology Department of the HUGTiP for their outstanding sample management and processing. We would like to thank V. Urrea from for his excellent statistical assistance.

\section{SUPPLEMENTARY MATERIAL}

The Supplementary Material for this article can be found online at: https://www.frontiersin.org/articles/10.3389/fimmu. 2019.00825/full\#supplementary-material

Movie 1 | 3D volumetric $x-y-z$ data field reconstruction of a Siglec- $1^{+}$cell from the cervical tissue of a viremic HIV-infected woman. Opacity representation of DAPI stained nuclei and fluorescence of the sac-like virus-containing compartment along with Siglec-1 staining.

Supplemental Figure 1 | Representative histograms of HLA-DR expression comparing the Siglec-1 positive and negative populations on $\mathrm{CD}^{-} \mathrm{CD}^{-} 1 \mathrm{c}^{+}$

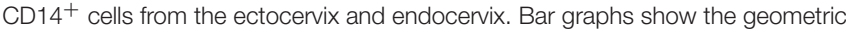
mean fluorescence values and SEM of HLA-DR expression from 14 donors. Statistical differences were assessed with a Wilcoxon matched-pairs signed rank test.

and infects intraepithelial dendritic cells. J Virol. (2000) 74:6087-95. doi: 10.1128/JVI.74.13.6087-6095.2000

8. Masurier C, Salomon B, Guettari N, Pioche C, Lachapelle F, Guigon M, et al. Dendritic cells route human immunodeficiency virus to lymph nodes after vaginal or intravenous administration to mice. J Virol. (1998) 72:7822-9.

9. Spira AI, Marx PA, Patterson BK, Mahoney J, Koup RA, Wolinsky SM, et al. Cellular targets of infection and route of viral dissemination after an intravaginal inoculation of simian immunodeficiency virus into rhesus macaques. J Exp Med. (1996) 183:215-25.

10. Cameron PU, Freudenthal PS, Barker JM, Gezelter S, Inaba K, Steinman RM. Dendritic cells exposed to human immunodeficiency virus type-1 transmit a vigorous cytopathic infection to CD4+ T cells. Science. (1992) 257:383-7.

11. Geijtenbeek TB, Kwon DS, Torensma R, van Vliet SJ, van Duijnhoven GC, Middel J, et al. DC-SIGN, a dendritic cell-specific HIV-1-binding protein that enhances trans-infection of T cells. Cell. (2000) 100:587-97. doi: 10.1016/S0092-8674(00)80694-7

12. Turville SG, Santos JJ, Frank I, Cameron PU, Wilkinson J, MirandaSaksena M, et al. Immunodeficiency virus uptake, turnover, and 2phase transfer in human dendritic cells. Blood. (2004) 103:2170-9. doi: 10.1182/blood-2003-09-3129 
13. Izquierdo-Useros N, Blanco J, Erkizia I, Fernandez-Figueras MT, Borras FE, Naranjo-Gomez M, et al. Maturation of blood-derived dendritic cells enhances human immunodeficiency virus type 1 capture and transmission. J Virol. (2007) 81:7559-70. doi: 10.1128/JVI.02572-06

14. Sanders RW, de Jong EC, Baldwin CE, Schuitemaker JH, Kapsenberg ML, Berkhout B. Differential transmission of human immunodeficiency virus type 1 by distinct subsets of effector dendritic cells. J Virol. (2002) 76:7812-21. doi: 10.1128/JVI.76.15.7812-7821.2002

15. Wang JH, Janas AM, Olson WJ, Wu L. Functionally distinct transmission of human immunodeficiency virus type 1 mediated by immature and mature dendritic cells. J Virol. (2007) 81:8933-43. doi: 10.1128/JVI.00878-07

16. Shen R, Kappes JC, Smythies LE, Richter HE, Novak L, Smith PD. Vaginal myeloid dendritic cells transmit founder HIV-1. J Virol. (2014) 88:7683-8. doi: 10.1128/JVI.00766-14

17. Trifonova RT, Bollman B, Barteneva NS, Lieberman J. Myeloid cells in intact human cervical explants capture HIV and can transmit It to CD4 T Cells. Front Immunol. (2018) 9:2719. doi: 10.3389/fimmu.2018. 02719

18. Rodriguez-Garcia M, Shen Z, Barr FD, Boesch AW, Ackerman ME, Kappes JC, et al. Dendritic cells from the human female reproductive tract rapidly capture and respond to HIV. Mucosal Immunol. (2017) 10:531-44. doi: $10.1038 / \mathrm{mi} .2016 .72$

19. Izquierdo-Useros N, Lorizate M, Puertas MC, Rodriguez-Plata MT, Zangger N, Erikson E, et al. Siglec-1 is a novel dendritic cell receptor that mediates HIV-1 trans-infection through recognition of viral membrane gangliosides. PLoS Biol. (2012) 10:e1001448. doi: 10.1371/journal.pbio.1001448

20. Puryear WB, Akiyama H, Geer SD, Ramirez NP, Yu X, Reinhard BM, et al. Interferon-inducible mechanism of dendritic cell-mediated HIV1 dissemination is dependent on Siglec-1/CD169. PLoS Pathog. (2013) 9:e1003291. doi: 10.1371/journal.ppat.1003291

21. Rempel H, Calosing C, Sun B, Pulliam L. Sialoadhesin expressed on IFNinduced monocytes binds HIV-1 and enhances infectivity. PLOS ONE. (2008) 3:e1967. doi: 10.1371/journal.pone.0001967

22. Yu HJ, Reuter MA, McDonald D. HIV traffics through a specialized, surface-accessible intracellular compartment during trans-infection of $\mathrm{T}$ cells by mature dendritic cells. PLoS Pathog. (2008) 4:e1000134. doi: 10.1371/journal.ppat.1000134

23. McDonald D, Wu L, Bohks SM, KewalRamani VN, Unutmaz D, Hope TJ. Recruitment of HIV and its receptors to dendritic cell-T cell junctions. Science. (2003) 300:1295-7. doi: 10.1126/science.1084238

24. Stieh DJ, Maric D, Kelley ZL, Anderson MR, Hattaway HZ, Beilfuss BA, et al. Vaginal challenge with an SIV-based dual reporter system reveals that infection can occur throughout the upper and lower female reproductive tract. PLoS Pathog. (2014) 10:e1004440. doi: 10.1371/journal.ppat.1004440

25. Brenchley JM, Price DA, Schacker TW, Asher TE, Silvestri G, Rao S, et al. Microbial translocation is a cause of systemic immune activation in chronic HIV infection. Nature Med. (2006) 12:1365-71. doi: 10.1038/nm1511

26. Puryear WB, Yu X, Ramirez NP, Reinhard BM, Gummuluru S. HIV-1 incorporation of host-cell-derived glycosphingolipid GM3 allows for capture by mature dendritic cells. Proc Nat Acad Sci USA. (2012) 109:7475-80. doi: 10.1073/pnas.1201104109

27. Sewald X, Ladinsky MS, Uchil PD, Beloor J, Pi R, Herrmann C, et al. Retroviruses use CD169-mediated trans-infection of permissive lymphocytes to establish infection. Science. (2015) 350:563-7. doi: 10.1126/science. aab2749

28. Trifonova RT, Lieberman J, van Baarle D. Distribution of immune cells in the human cervix and implications for HIV transmission. Am J Reproduct Immunol. (2014) 71:252-64. doi: 10.1111/aji.12198

29. Duluc D, Gannevat J, Anguiano E, Zurawski S, Carley M, Boreham M, et al. Functional diversity of human vaginal APC subsets in directing T-cell responses. Mucosal Immunol. (2013) 6:626-38. doi: 10.1038/mi. 2012.104

30. Izquierdo-Useros N, Lorizate M, Contreras FX, Rodriguez-Plata MT, Glass B, Erkizia I, et al. Sialyllactose in viral membrane gangliosides is a novel molecular recognition pattern for mature dendritic cell capture of HIV-1. PLoS Biol. (2012) 10:e1001315. doi: 10.1371/journal.pbio.1001315

31. Pino M, Erkizia I, Benet S, Erikson E, Fernandez-Figueras MT, Guerrero D, et al. HIV-1 immune activation induces Siglec-1 expression and enhances viral trans-infection in blood and tissue myeloid cells. Retrovirology. (2015) 12:37. doi: 10.1186/s12977-015-0160-x

32. Soper A, Kimura I, Nagaoka S, Konno Y, Yamamoto K, Koyanagi $\mathrm{Y}$, et al. Type I interferon responses by HIV-1 infection: association with disease progression and control. Front Immunol. (2017) 8:1823. doi: 10.3389/fimmu.2017.01823

33. Li Q, Estes JD, Schlievert PM, Duan L, Brosnahan AJ, Southern PJ, et al Glycerol monolaurate prevents mucosal SIV transmission. Nature. (2009) 458:1034-8. doi: 10.1038/nature07831

34. Cantero J, Genesca M. Maximizing the immunological output of the cervicovaginal explant model. J Immunol Methods. (2018) 460, 26-35. doi: 10.1016/j.jim.2018.06.005

35. Ballweber L, Robinson B, Kreger A, Fialkow M, Lentz G, McElrath MJ, et al. Vaginal langerhans cells nonproductively transporting HIV-1 mediate infection of T cells. J Virol. (2011) 85:13443-7. doi: 10.1128/JVI.05615-11

36. Pope M, Betjes MG, Romani N, Hirmand H, Cameron PU, Hoffman L, et al. Conjugates of dendritic cells and memory $\mathrm{T}$ lymphocytes from skin facilitate productive infection with HIV-1. Cell. (1994) 78:389-98.

37. Iwasaki A. Mucosal dendritic cells. Ann Rev Immunol. (2007) 25:381-418. doi: 10.1146/annurev.immunol.25.022106.141634

38. Boggiano C, Manel N, Littman DR. Dendritic cell-mediated trans-enhancement of human immunodeficiency virus type 1 infectivity is independent of DC-SIGN. J Virol. (2007) 81:2519-23. doi: 10.1128/JVI.01661-06

39. Granelli-Piperno A, Pritsker A, Pack M, Shimeliovich I, Arrighi JF, Park CG, et al. Dendritic cell-specific intercellular adhesion molecule 3-grabbing nonintegrin/CD209 is abundant on macrophages in the normal human lymph node and is not required for dendritic cell stimulation of the mixed leukocyte reaction. J Immunol. (2005) 175:4265-73. doi: 10.4049/jimmunol.175.7.4265

40. Trumpfheller C, Park CG, Finke J, Steinman RM, Granelli-Piperno A. Cell type-dependent retention and transmission of HIV-1 by DC-SIGN. Int Immunol. (2003) 15:289-98. doi: 10.1093/intimm/dxg030

41. Turville SG, Cameron PU, Handley A, Lin G, Pohlmann S, Doms RW, et al. Diversity of receptors binding HIV on dendritic cell subsets. Nat Immunol. (2002) 3:975-83. doi: 10.1038/ni841

42. Wu L, Bashirova AA, Martin TD, Villamide L, Mehlhop E, Chertov AO, et al. Rhesus macaque dendritic cells efficiently transmit primate lentiviruses independently of DC-SIGN. Proc Nat Acad Sci USA. (2002) 99:1568-73. doi: $10.1073 /$ pnas.032654399

43. Gummuluru S, Rogel M, Stamatatos L, Emerman M. Binding of human immunodeficiency virus type 1 to immature dendritic cells can occur independently of DC-SIGN and mannose binding C-type lectin receptors via a cholesterol-dependent pathway. J Virol. (2003) 77:12865-74. doi: 10.1128/JVI.77.23.12865-12874.2003

44. Doyle T, Goujon C, Malim MH. HIV-1 and interferons: who's interfering with whom? Nat Rev Microbiol. (2015) 13:403-13. doi: 10.1038/nrmicro3449

45. Hickey DK, Patel MV, Fahey JV, Wira CR. Innate and adaptive immunity at mucosal surfaces of the female reproductive tract: stratification and integration of immune protection against the transmission of sexually transmitted infections. J Reproduct Immunol. (2011) 88:185-94. doi: 10.1016/j.jri.2011.01.005

46. Iwasaki A. Antiviral immune responses in the genital tract: clues for vaccines Nat Rev Immunol. (2010) 10:699-711. doi: 10.1038/nri2836

47. Iyer SS, Bibollet-Ruche F, Sherrill-Mix S, Learn GH, Plenderleith L, Smith $\mathrm{AG}$, et al. Resistance to type 1 interferons is a major determinant of HIV-1 transmission fitness. Proc Nat Acad Sci USA. (2017) 114:E590-E9. doi: 10.1073/pnas.1620144114

48. Beignon AS, McKenna K, Skoberne M, Manches O, DaSilva I, Kavanagh DG, et al. Endocytosis of HIV-1 activates plasmacytoid dendritic cells via Toll-like receptor-viral RNA interactions. J Clin Invest. (2005) 115:3265-75. doi: 10.1172/JCI26032

49. Yonezawa A, Morita R, Takaori-Kondo A, Kadowaki N, Kitawaki $\mathrm{T}$, Hori $\mathrm{T}$, et al. Natural alpha interferon-producing cells respond to human immunodeficiency virus type 1 with alpha interferon production and maturation into dendritic cells. J Virol. (2003) 77:3777-84. doi: 10.1128/JVI.77.6.3777-3784.2003

50. Meier A, Chang JJ, Chan ES, Pollard RB, Sidhu HK, Kulkarni S, et al. Sex differences in the Toll-like receptor-mediated response of 
plasmacytoid dendritic cells to HIV-1. Nat Med. (2009) 15:955-9. doi: 10.1038/ $\mathrm{nm} .2004$

51. Chang JJ, Woods M, Lindsay RJ, Doyle EH, Griesbeck M, Chan ES, et al. Higher expression of several interferon-stimulated genes in HIV-1-infected females after adjusting for the level of viral replication. J Infect Dis. (2013) 208:830-8. doi: 10.1093/infdis/jit262

52. Abel K, Rocke DM, Chohan B, Fritts L, Miller CJ. Temporal and anatomic relationship between virus replication and cytokine gene expression after vaginal simian immunodeficiency virus infection. J Virol. (2005) 79:12164-72. doi: 10.1128/JVI.79.19.12164-12172.2005

53. Hirbod T, Nilsson J, Andersson S, Uberti-Foppa C, Ferrari D, Manghi M, et al. Upregulation of interferon-alpha and RANTES in the cervix of HIV1-seronegative women with high-risk behavior. J Acqu Immune Def Syndrom. (2006) 43:137-43. doi: 10.1097/01.qai.0000229016.85192.60

54. Wang Y, Abel K, Lantz K, Krieg AM, McChesney MB, Miller CJ. The Toll-like receptor 7 (TLR7) agonist, imiquimod, and the TLR9 agonist, $\mathrm{CpG}$ ODN, induce antiviral cytokines and chemokines but do not prevent vaginal transmission of simian immunodeficiency virus when applied intravaginally to rhesus macaques. J Virol. (2005) 79:14355-70. doi: 10.1128/JVI.79.22.14355-14370.2005

55. Agrawal T, Vats V, Wallace PK, Singh A, Salhan S, Mittal A. Recruitment of myeloid and plasmacytoid dendritic cells in cervical mucosa during Chlamydia trachomatis infection. Clin Microbiol Infect. (2009) 15:50-9. doi: 10.1111/j.1469-0691.2008.02113.x

56. Lund JM, Linehan MM, Iijima N, Iwasaki A. Cutting edge: plasmacytoid dendritic cells provide innate immune protection against mucosal viral infection in situ. J Immunol. (2006) 177:7510-4. doi: $10.4049 /$ jimmunol.177.11.7510
57. Segura E, Touzot M, Bohineust A, Cappuccio A, Chiocchia G, Hosmalin A, et al. Human inflammatory dendritic cells induce Th17 cell differentiation. Immunity. (2013) 38:336-48. doi: 10.1016/j.immuni.2012. 10.018

58. Stieh DJ, Matias E, Xu H, Fought AJ, Blanchard JL, Marx PA, et al. Th17 Cells are preferentially infected very early after vaginal transmission of SIV in macaques. Cell Host Microbe. (2016) 19:529-40. doi: 10.1016/j.chom.2016.03.005

59. Blanco J, Barretina J, Clotet B, Este JA. R5 HIV gp120-mediated cellular contacts induce the death of single CCR5-expressing CD4 T cells by a gp41-dependent mechanism. J Leuk Biol. (2004) 76:804-11. doi: $10.1189 /$ jlb.0204100

Conflict of Interest Statement: A patent application based on this work has been filed (US 62/832,054). The authors declare that no other competing financial interests exist and that the research was conducted in the absence of any commercial or financial relationships that could be construed as a potential conflict of interest.

Copyright (C) 2019 Perez-Zsolt, Cantero-Pérez, Erkizia, Benet, Pino, SerraPeinado, Hernández-Gallego, Castellví, Tapia, Arnau-Saz, Garrido, Tarrats, Buzón Martinez-Picado, Izquierdo-Useros and Genescà. This is an open-access article distributed under the terms of the Creative Commons Attribution License (CC BY). The use, distribution or reproduction in other forums is permitted, provided the original author(s) and the copyright owner(s) are credited and that the original publication in this journal is cited, in accordance with accepted academic practice. No use, distribution or reproduction is permitted which does not comply with these terms. 